LA W RENCE LIVERM ORE N A TIO NAL LABORATORY
Concept of Operations for Nuclear Warhead Embedded Sensors

P. D. Rockett, T. R. Koncher

May 17, 2012 
This document was prepared as an account of work sponsored by an agency of the United States government. Neither the United States government nor Lawrence Livermore National Security, LLC, nor any of their employees makes any warranty, expressed or implied, or assumes any legal liability or responsibility for the accuracy, completeness, or usefulness of any information, apparatus, product, or process disclosed, or represents that its use would not infringe privately owned rights. Reference herein to any specific commercial product, process, or service by trade name, trademark, manufacturer, or otherwise does not necessarily constitute or imply its endorsement, recommendation, or favoring by the United States government or Lawrence Livermore National Security, LLC. The views and opinions of authors expressed herein do not necessarily state or reflect those of the United States government or Lawrence Livermore National Security, LLC, and shall not be used for advertising or product endorsement purposes.

This work performed under the auspices of the U.S. Department of Energy by Lawrence Livermore National Laboratory under Contract DE-AC52-07NA27344. 


\title{
Concept of Operations for Nuclear Warhead Embedded Sensors
}

\author{
Paul Rockett and T. R. Koncher \\ June 15,2012
}

\section{Introduction}

Embedded arms-control-sensors provide a powerful new paradigm for managing compliance with future nuclear weapons treaties, where deployed warhead numbers will be reduced to 1000 or less. The CONOPS (Concept of Operations) for use with these sensors is a practical tool with which one may help define design parameters, including size, power, resolution, communications, and physical structure. How frequently must data be acquired and must a human be present? Will such data be acquired for only stored weapons or will it be required of deployed weapons as well? Will tactical weapons be subject to such monitoring or will only strategic weapons apply? Which data will be most crucial? Will OSI's be a component of embedded sensor data management or will these sensors stand alone in their data extraction processes? The problem space is massive, but can be constrained by extrapolating to a reasonable future treaty regime and examining the bounded options this scenario poses.

When President G. H. W. Bush and Secretary M. Gorbachev signed STARTI in 1991, US and RF nuclear arsenals totaled about 50,000 warheads. They could hardly have imagined a time when their nuclear arsenals would reach a few thousands of deployed warheads, let alone hundreds or zero. Yet New START signed in 2010 will bring each country's deployed stockpiles to 1550 warheads by 2019 , and independent discussions are ongoing regarding reductions that could go all the way to zero. In 2007 Kissinger, Schulz, Perry, and Nunn wrote an Op Ed piece in the New York Times in which they argued for "a world free of nuclear weapons."

The Embedded Warhead Sensors project addresses warhead accounting for reductions by placing arms control monitors within the warhead body (aeroshell of an Reentry Vehicle or the exterior case of a gravity bomb) to track and identify warheads regardless of their position within their lifecycle. This project's sensors will consist of detectors confirming the presence of SNM and possibly its approximate mass, the presence of HE, a unique identifier, and a possible tamper indicator. While these may not be arguably sufficient to confirm the presence of a nuclear weapon, they constitute an adequate beginning to establishing the feasibility of emplacing such sensors within an operational warhead. Such presence will require total adherence to the safety, security, surety, and reliability requirements that face warhead design. It will also serve to identify sensor communications and power architectures that can confidently function in a warhead environment. (Note that the CY2012 US/UK Dismantlement Exercise concluded that warhead verification should include SNM presence, SNM mass, relevant isotope ratios, 
HE presence, and some level of configuration knowledge. The Embedded Sensors project incorporates three of those five.)

Serious challenges exist in sustaining strategic stability in a world with fewer, but not zero, nuclear weapons, and thus all postulated scenarios mandate some form of close monitoring to maintain confidence that breakout will be difficult and that treaty-limited items (TLIs) will in fact be fully accounted for. STARTI took a highly creative approach to arms reduction, eliminating the platforms for nuclear weapons, rather than the weapons themselves. Missiles, launchers, aircraft, and silos were destroyed under On-site Inspections (OSI) to assure the improbable re-use of these devices. They were easy to identify, difficult to hide, and relatively simple to render inoperable. In treaties beyond New START, however, the small size and ease of concealing warheads will mandate that they themselves will be the TLI, rendering compliance monitoring administratively and technically challenging.

\section{Verification Regime Objectives}

As warhead numbers move to 1000 and below, issues of breakout, hidden storage, and tracking of specific TLIs may critically impact the stability of the arms control regime. Verification will require a high level of confidence in both numbers and geolocation, and the frequency of re-assurance and reporting may be higher than under STARTI where most TLIs were not highly mobile. A firm continuity-of-knowledge will be needed to secure such a regime, and authentication of transmitted data will support the needed high confidence that declarations are being adhered to faithfully. Verification must be able to distinguish legal from illicit warheads, and should be able to indicate that warheads are not being counted more than once. As in prior treaties, NTM will provide a backbone of cueing information to enhance the confidence of treaty parties. Thus a goal of this rigorous regime will be to strongly discourage cheating by raising significant barriers to doing so.

Stated simply the objectives of our postulated arms control regime shall be:

1. Incorporate monitoring into the treaty regime

2. Demand high confidence in the knowledge of warhead numbers and geolocation

3. Have high confidence that the item reporting via Embedded Sensors is in fact a declared nuclear warhead.

4. Enable rigorous accountability in

a. total aggregate numbers of warheads

b. accountable subsets, depending upon warhead type may include

i. Associated with particular weapons platforms

ii. ID number of warhead

iii. Tactical v. strategic

iv. Deployed v. non-deployed

v. Naval

c. geolocation numbers - options

\section{LLNL-TR-557811}


i. set limits by zone

ii. set limits by bases

iii. set limits by category - awaiting dismantlement, disposal, re-use, separated into components

5. Distinguish between legal and illicit warheads

6. Render conditions such that parties would have to take extreme measures to violate the treaty and hide warheads

7. Provide regular observations using NTM

A few comments are warranted. The most important measurable will be the total aggregate number of warheads. In the long run the goal of any arms reduction treaty (to zero order) is simply to reduce the numbers of arms. While one could argue that kilotonnage or strategic types or a balanced set of weapon types might be more strategically sound, aggregate numbers are far simpler and more achievable in a negotiating environment. To first order, reductions of warheads on aircraft, land-based missiles, or at sea need to be separately counted due their unique storage, life-cycling, and platform requirements. Lastly, "aggregate" numbers must include both tactical as well as strategic warheads, as well as deployed and non-deployed.

To avoid double counting of warheads there should be a verifiable technique to make a unique identification of a specific warhead, essentially an electronic barcode figuratively stenciled onto the "tail" like a fingerprint that cannot be spoofed. A warhead ID would go a long way to aid in distinguishing between a declared TLI and an illicit or undeclared TLI.

\section{Operational Requirements}

Embedded sensors will be compact, low power, rugged, periodically reporting arms control instruments that will provide verification that an item is a nuclear warhead, and that it is a specific warhead. They will be literally embedded within the warhead aeroshell or bomb case, and can report on a regular basis regarding ID and weapon state.

They will not identify the type of warhead, nor will they indicate whether it is strategic, tactical, deployed, or non-deployed. Avoidance of typing supports the intent to address aggregate numbers of warheads, regardless of type. Geolocation will be provided by an intermediate data collection and transmission system, which will forward this information to a central collection center in-country. This information will be vetted and handed to a Bilateral Consultative Commission (BCC) for transmission to the other States Party.

For the purposes of this project it will be assumed that monitoring will be performed for ALL stored, non-deployed warheads of both tactical and strategic types. The Embedded 
Sensors concept may also be applied to deployed warheads, if geolocation is removed, and communication is limited in scope. ${ }^{1}$

Embedded Sensors will be purely passive, unable to collect and transmit data without an external power source. This will assure that deployed warheads will not be able to divulge location or component status while at sea or on a mobile platform.

To achieve high confidence of reported information such sensors will need to be present during the full warhead lifetime, "cradle to grave." Warheads may be out of communications during moves, but will have reports produced prior to departure and again at delivery, retaining confidence that the weapon moved was the same as that delivered. Placement of arms control sensors will occur either during initial production or during Life Extension Programs, and must remain in place, highly inaccessible, until dismantlement of the weapon. Since Embedded Sensors will enable communication outside of the weapon case, the other States Party would encounter the warhead before initial shipment and authenticate sensor operation with methods known only to that Party.

Regular reporting at rates, such as once a week to once a month, as agreed will enable data to become a component of a formal Continuity of Knowledge (CoK) regime. Such frequent reporting, including location, will be added to NTM observations, occasional OSIs, and declarations to establish data credibility. Prior history from earlier CoK observations will be correlated to confirm reported data. Long times inbetween reports will permit the slow, but regular buildup of data, which could be locally obtained as frequently as once/day, keeping power requirements to a minimum. It should be noted that New START data exchanges take place every six months, as did those under START1, so that monthly reporting would constitute a dramatic increase in data flow for a new treaty regime.

Considering the time required for internal vetting of data before transmission to the other States Party, this CONOPS will utilize one month as the period for reporting. (In addition special reporting will be required prior to a TLI move and immediately following it arrival in a new location.) Data will be acquired, authenticated, and pushed out automatically without human intervention. A manual option may wish to be included in cases of an OSI and/or a move.

On-site Inspections typically operate by confirming the presence of specific treatylimited-items, selected randomly (or otherwise) shortly before the inspection. In the presence of Embedded Sensors inspectors could continue this practice, and include a special readout from a given warhead to confirm its "state" as a warhead along with its unique identifier.

${ }^{1}$ SLBMs would only report while in port. Warheads on fixed launchers could report on the same cycle as stored warheads. Mobile launcher warheads would have to evaluate the limits needed on communications to avoid revealing location.

\section{LLNL-TR-557811}


The data produced by the embedded arms control sensors must be unique for each warhead, in order to both characterize its "state" as a nuclear warhead and identify it as a particular warhead. Given the large numbers of warheads (possibly in the low thousands), it will be important that Continuity of Knowledge is maintained for each TLI. This will require both a unique identifying number, as well as data regarding the device SNM and HE, which should provide distinctive signals that together with the numerical identifier will maintain confidence that this is a legitimate, declared TLI.

To avoid the possibility of extracting sensitive information, the SNM and HE data must be sufficiently simple and sparse that no or little further information can be extracted. This "inherent information barrier" will sustain confidence that design information is not compromised, and that all the data is shareable among the treaty partners. Authentication of all communicated data will add the next layer of trust that the data packet is credible, not artificially generated, and truly represents a picture of the state of a particular TLI.

There is always the possibility that non-confirming data or zero data will return from an Embedded Sensor, due to a sensor failure. Under present rules, such a variation would be reported to the other States Party and the BCC would attempt resolution. As sound and reliable as sensors may be built, even a 0.999 /year reliability could result in 1-5 failures per year across the entire stockpile. To avoid rashly raising the importance of apparently negative data, such incidents shall result in rechecks in 30 days. During this waiting time intermediate transmission sources will be checked to identify the source of the problem. If the sensors are at fault, and/or all sensors cease functioning, the warhead will be flagged during regular verification monitoring and will return to a standard OSImonitored item.

Insertion of these sensors and the credibility of their data will mandate joint development of this technology. Just as the Fission Meter (for SNM detection) was developed and patented in both the US and the Russian Federation, so Embedded arms control Sensors will need to be studied, tested, and evaluated by both States Parties in order to achieve a sufficient level of trustworthiness and acceptance. Sensor requirements for Russian warheads may vary non-trivially from US because of the significant asymmetry between their and our weapons lifecycle. Joint development should assure that both Parties feel their own needs are met, and that their data is sufficiently shareable.

\section{Warhead and Embedded Sensors Lifecycle}

Installation of Embedded arms control Sensors should take place during warhead assembly and/or LEPs. Plant access may be required for the other States Party to initiate authentication of sensor data via installation of a private key. This is envisioned to be one of the last tasks in warhead production, before hand-off to the military. Fifteen years ago Pantex examined the issues related to Russian inspectors inside their fence. Thus the presence of another States Party within otherwise secure areas has been well considered. 
After passage to military hands, chain-of-custody of the warhead may occur at storage facilities, upon fixed or mobile missile launchers, or on-board a submarine. Since the key to the strategic strength of mobile platforms is their effective invisibility, mobile launchers and submarines at sea will not be considered to be a part of the verification regime, except for specified times during which the States Parties agree to present the warheads for inspection, on-site or reporting using the Embedded arms control Sensors. It should be noted that deployed warheads upon fixed missile launchers could continue to have active readouts from Embedded Sensors, since, in principle, treaty implemented declarations would indicate their presence at a particular missile operating base anyway. At end-of-life the same warhead will be moved to a dismantlement facility, raising further issues related to when Embedded Sensors will provide the last data point and how and if components will be tracked following disassembly.

Thus consideration for operation of Embedded arms control Sensors should be given at the:

- Production facility - nondeployed

- Storage sites - nondeployed

- Missile operating base - nondeployed and deployed

- Immediately prior to and following transportation of the warhead - nondeployed

- Special reporting periods for mobile platforms at specified locations - deployed

- Dismantlement facilities - nondeployed.

The data acquired from Embedded arms control Sensors may generate questions, regarding uniqueness and/or accuracy. To sustain confidence in the numbers such data will need to be correlated with other sources of information, esp. NTM, on-site inspections, and past inspection history. NTM may provide insight to moves made to or from storage and inform the observing States Party regarding the movement of equipment into or out of the storage area. Boots on the ground will never go away (at least in this CONOPS) and OSIs will continue to be needed to provide an added layer of validation to assure that items observed in the past are still as declared in terms of location and item ID. With Embedded Sensors providing regular reporting for verification and chain-ofcustody, the frequency of OSIs may be reduced from the "up to" eighteen per year under New START. When warheads become TLIs, we will continue to have air, ICBM, and SLBM bases subject to inspection, but now we need to add all storage sites and production sites. Thus the total number of required OSIs will not disappear, but hopefully may be reduced from the number of inspections that might have been required without Embedded Sensors.

At the end-of-life a final validation of the Embedded Sensors will be needed prior to disassembly. Knowledge of each States Parties' warhead lifecycles will be crucial to assure that such a final check is viable and acceptable. One may wish to hand over the warhead's Embedded Sensors to the other State Party for inspection and certification. Given the great difference in US and Russian warhead life cycle practices, it will 
important to exchange such information with sufficient detail to support decisions about where end-of-life takes place for each party.

\section{Summary}

Arms control verification sensors, embedded within the warhead case or aeroshell, must provide sufficient but not excessively detailed data, confirming that the item is a nuclear warhead and that it is a particular warhead without revealing sensitive information.

Geolocation will be provided by an intermediate transceiver used to acquire the data and to forward the data to a central processing location. Past Chain-of-Custody projects have included such devices and will be primarily responsible for adding such indicators in the future. ${ }^{2}$ For the purposes of a treaty regime a TLI will be verified as a nuclear warhead by knowledge of a) the presence and mass of SNM, b) the presence of HE, and 3) the reporting of a unique tag ID. All of these parameters can be obtained via neutron correlation measurements, Raman spectroscopy, and fiber optic grating fabrication, respectively.

Data from these sensors will be pushed out monthly and acquired nearly daily, providing one of several verification layers in depth, including on-site inspections, NTM, declarations, and semi-annual BCC meetings. Human intervention will not be necessary. The sheer numbers, small size, and wide distribution of warhead TLIs will mandate the added level of remote monitoring that Embedded Sensors can provide. This multilayer protection will limit the need to increase the frequency of OSIs, by adding confidence that declared TLIs remain as declared and that no undeclared items enter the regime without the other States Party's knowledge.

Acceptance of Embedded arms control Sensor technologies will require joint development by all State's Parties involved. Principles of operation and robustness of technologies must be individually evaluated to sustain confidence in the strength of this system against attack. Weapons designers must be assured that these sensors will in no way impact weapon performance and operation, will not affect weapons security and safety, and will have a neutral impact upon weapon system surety. Each State's Party will need to conduct an in depth review of their weapons' lifecycle to determine where moves may be reduced to minimize vulnerabilities and where random selection may be used to minimize the ability to make undeclared changes. In the end Verification is a political measure, not a technical one. If the potential users can gain sufficient confidence in the application of Embedded arms control Sensors, they could constitute the final layer of glue to hold together the next Nuclear Arms Control agreement.

\footnotetext{
${ }^{2}$ Warhead Monitoring Technology Program conducted at Sandia National Laboratories under funding by DTRA during 1998-2003.
}

LLNL-TR-557811 
This work performed under the auspices of the U.S. Department of Energy by Lawrence Livermore National Laboratory under Contract DE-AC52-07NA27344.

This document was prepared as an account of work sponsored by an agency of the United States government. Neither the United States government nor Lawrence Livermore National Security, LLC, nor any of their employees makes any warranty, expressed or implied, or assumes any legal liability or responsibility for the accuracy, completeness, or usefulness of any information, apparatus, product, or process disclosed, or represents that its use would not infringe privately owned rights. Reference herein to any specific commercial product, process, or service by trade name, trademark, manufacturer, or otherwise does not necessarily constitute or imply its endorsement, recommendation, or favoring by the United States government or Lawrence Livermore National Security, LLC. The views and opinions of authors expressed herein do not necessarily state or reflect those of the United States government or Lawrence Livermore National Security, LLC, and shall not be used for advertising or product endorsement purposes. 